\title{
False-Positive Results of Serological Tests for Allergy in Alcoholic Patients
}

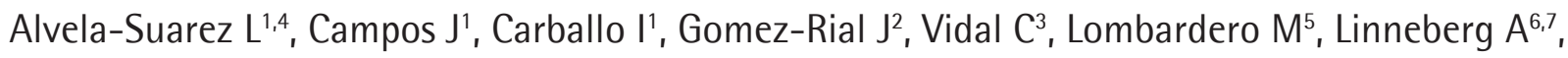 \\ Gonzalez-Quintela $\mathrm{A}^{1}$
}

\author{
'Department of Internal Medicine, Complejo Hospitalario, University of Santiago de Compostela, Spain \\ 2Department of Immunology, Complejo Hospitalario, University of Santiago de Compostela, Spain \\ ${ }^{3}$ Department of Allergy, Complejo Hospitalario, University of Santiago de Compostela, Spain \\ ${ }^{4} \mathrm{HM}-\mathrm{Hospital}$ La Rosaleda, Santiago de Compostela, Spain \\ ${ }^{5}$ CMC REDD Department, ALK-Abelló S.A., Madrid, Spain \\ ${ }^{6}$ Research Centre for Prevention and Health, Rigshospitalet, Glostrup, Denmark \\ ${ }^{7}$ Department of Clinical Medicine, Faculty of Health and Medical Sciences, University of Copenhagen, Copenhagen, Denmark
}

J Investig Allergol Clin Immunol 2019; Vol. 29(3): 213-221

doi: 10.18176/jiaci.0309

\begin{abstract}
Background: Alcohol consumption is associated with enhanced $T_{H} 2$ immune responses.

Objective: To investigate the frequency of false-positive results in serological tests for allergy in alcoholic patients.

Methods: A total of 138 alcoholic patients consecutively admitted to hospital underwent a panel of allergy tests that included serum total $\lg \mathrm{E}$, a multiallergen IgE test (UniCAP Phadiatop), and skin prick tests to relevant aeroallergens in the area, which were considered the standard reference for atopy. In selected cases with positive specific $\lg E$ (slgE) to cross-reactive carbohydrate determinants (CCDs) on ImmunoCAP, we determined slgE to hymenoptera venom components (ADVIA Centaur) and a microarray of 103 allergen components (ISAC). Results: Increased serum total IgE (>170 IU/mL) was observed in 59/110 (54\%) of nonatopic (skin prick test-negative) patients. The result of the multiallergen IgE test was positive in 46 nonatopic patients (42\%). This finding was closely associated with high serum concentrations of total lgE and slgE to CCDs. The vast majority of patients with positive CCD-slgE showed positivity to glycosylated plant and hymenoptera allergen components on ISAC and ADVIA Centaur. Only 1 out of 26 patients with positive slgE to CCD and hymenoptera venom developed honeybee venom allergy after a median follow-up of 166 months. Correlations between measurements of slgE to CCD markers on ImmunoCAP, ADVIA Centaur, and ISAC were imperfect.

Conclusions: Serological tests for allergy should be interpreted with caution in alcoholic patients, who frequently have increased levels of total IgE and CCD-slgE and subsequent positivity of slgE to glycosylated allergen components, irrespective of the method used.
\end{abstract}

Key words: Alcohol. Cross-reactive carbohydrate determinants. Allergy. Glycans. Specific lgE. Total IgE.

\section{Resumen}

Antecedentes: El consumo de alcohol se asocia con respuestas inmunes aumentadas de tipo Th2.

Objetivo: Investigar la frecuencia de falsos positivos en los tests serológicos de alergia en alcohólicos.

Métodos: En un total de 138 pacientes alcohólicos ingresados en el hospital de forma consecutiva se realizó un panel de pruebas de alergia que incluyó la determinación de IgE sérica total, un test de IgE específica multialergeno (UniCAP Phadiatop) y pruebas cutáneas en prick a una batería de aeroalérgenos relevantes en el área, cuya positividad se consideró la referencia para clasificar a los pacientes como atópicos. En casos seleccionados con positividad de lgE específica (slgE) frente a carbohidratos con reactividad (CCDs) en el ImmunoCAP, se determinó la slgE a componentes del veneno de hymenópteros (ADVIA Centaur) y a un microarray de 103 componentes alergénicos (ISAC). Resultados: Se observó un aumento de las concentraciones de lgE sérica total (>170 IU/mL) en 59/110 (54\%) de los alcohólicos no atópicos (prick test-negativos). Cuarenta y seis alcohólicos no atópicos (42\%) presentaban un test de IgE específica multialérgeno positivo. Este hallazgo estuvo estrechamente asociado con la presencia de concentraciones elevadas de lgE total y de slgE a CCDs. La gran mayoría de los alcohólicos con positividad de slgE a CCDs mostraron positividad con componentes moleculares glicosilados de plantas e himenópteros en el ISAC y el ADVIA Centaur. Sólo uno de los 26 pacientes con positividad de slgE a CCDs e himenópteros desarrolló alergia clínica a picadura de abeja tras un seguimiento mediano de 166 meses. La correlación de las determinaciones de slgE a marcadores de CCD en ImmunoCAP, ADVIA Centaur e ISAC fue imperfecta.

Conclusiones: Los tests serológicos de alergia se deben interpretar con precaución en pacientes alcohólicos, que frecuentemente muestran elevación de IgE total, positividad de slgE a CCDs y, consecuentemente, positividad de slgE a componentes alergénicos glicosilados, independientemente del método utilizado.

Palabras clave: Alcohol. Carbohidratos con reactividad cruzada. Alergia. Glicanos. IgE específica. IgE total. 


\section{Introduction}

Alcohol is a psychoactive substance with dependenceproducing properties that has been widely used in many societies for centuries. The systemic effects of alcohol consumption include changes in innate and adaptative immune responses [1]. These alterations are directly related to the effects of ethanol on immune cells and to enhanced intestinal absorption of microbial products, specifically lipopolysaccharide, a component of gram-negative bacteria [2]. Previous studies have shown that ethanol can induce profound changes in both $\mathrm{T}_{\mathrm{H}} 1$ and $\mathrm{T}_{\mathrm{H}} 2$ cytokine production, with predominant $\mathrm{T}_{\mathrm{H}} 2$-driven phenomena $[3,4]$. Accordingly, administration of alcohol to rodents is followed shortly after by a significant increase in serum $\operatorname{IgE}$ concentrations [5]. In humans, total serum $\operatorname{IgE}$ is increased in most alcoholic patients [3,4,6-8] and is independent of liver disease [7]. The effect of alcohol on total IgE can also be observed in moderate alcohol consumers from general populations [9-11]. This effect is independent of the effect of smoking $[9,10]$. Moreover, total serum IgE tends to decrease after abstinence [7]. Lastly, an increase in cord blood $\operatorname{IgE}$ is observed in children born to mothers who consume alcohol during pregnancy [12].

The possible association between alcohol consumption and allergic sensitization or allergic disease is controversial [6,9-11]. Alcohol consumption (particularly alcohol abuse) is consistently associated with the presence of serum-specific $\operatorname{IgE}(\mathrm{sIgE})$ to $\mathrm{N}$-glycans from plant and invertebrate allergens, the so-called cross-reactive carbohydrate determinants (CCDs) [13-16]. CCDs are oligosaccharide side chains that are N-linked to asparagine residues in glycoproteins, which are gaining attention as IgE-binding structures $[17,18]$. These CCDs are widespread in nature, particularly in pollens, foods, insect proteins, and parasites $[17,18]$. The currently held view is that $\operatorname{IgE}$ antibodies to CCDs display poor biological activity because they are associated with neither positive skin prick test (SPT) results nor clinical symptoms $[17,18]$. However, CCD-sIgE can interfere with in vitro determinations by inducing extensive reactivity to plant, insect, and helminth allergens [17,18].

Serological tools for allergy diagnosis include determination of total IgE, sIgE to whole allergen extracts, multiallergen $\operatorname{sgE}$ tests that are intended for allergy screening, and determination of sIgE to allergen components, all of which make up the socalled molecular diagnosis of allergy [19]. The last approach includes determination of sIgE to individual molecular components and the use of microarrays. Microarray-based testing uses a small number of serum samples and enables clinicians to determine sIgE antibodies against multiple recombinant or purified natural allergen components in a single assay $[19,20]$. These tests should take interference by CCD into account when they are based on naturally glycosylated molecules or molecules obtained by recombination in microorganisms that involve glycosylation [17]. Interference might differ depending on the number of epitopes (mixture of allergens, single allergens, or allergen components) and the commercial method used [18]. This study sought to evaluate total IgE, sIgE to allergen extracts, multiallergen sIgE tests, and sIgE to single and microarray-based allergen components in alcoholic patients.

\section{Methods}

\section{Study Design and Participants}

This observational study was based on a previous survey on heavy drinkers consecutively admitted to the Internal Medicine Department of the University Teaching Hospital of Santiago de Compostela, Santiago de Compostela, Spain with a catchment area of approximately 500000 people [21]. Previous reports based on this cohort include the study of atopy traits in relation to CD14 gene polymorphisms [8] and the study of sensitization to CCD-sIgE in combination with a survey of the general adult population [13]. Briefly, 138 out of 145 patients with a history of current chronic alcohol abuse admitted over a 2.5-year period agreed to participate in the study. The median age of the participants was 47 (range, 27-78) years. Males accounted for 103 patients $(74.6 \%)$. Median average alcohol intake was 120 (range, 50-300) g/day (equivalent to 12 units). The main reasons for hospital admission were alcohol withdrawal syndrome (67 patients), complications of advanced liver disease (35 patients), alcoholic hepatitis (20 patients), and miscellaneous causes in the remaining 16 patients. After a week in hospital, the participants signed an informed consent form, completed an interviewer-administered structured questionnaire, underwent a panel of SPTs to aeroallergens, and had a blood sample taken for allergy studies (frozen until testing). These tests included sIgE to hymenoptera venom (whole venom and components), sIgE to aeroallergens, sIgE to CCD markers, and sIgE to a microarray of allergen components (see below). No patient in the series reported systemic reactions to hymenoptera stings at baseline in 2002-2004. The clinical records were reviewed in 2018, and the incidence of systemic reactions to hymenoptera stings was registered. The study was reviewed and approved by the Institutional Review Board and conformed to the Declaration of Helsinki.

\section{Skin Prick Tests}

In all cases, a panel of SPTs to respiratory allergens of local relevance was performed following standard procedures [8]. The panel included mites (Dermatophagoides pteronyssinus, Lepidoglyphus destructor, Tyrophagus putrescentiae), pollens (Lolium perenne, Plantago lanceolata, Betula alba, Parietaria judaica), molds (Alternaria alternata), and pet dander (dog and cat). Wheals $\geq 4 \mathrm{~mm}$ after 15 minutes were considered indicative of a positive reaction. Patients with at least 1 positive SPT result ( $\mathrm{n}=28,20 \%)$ were considered atopic.

\section{Serum Total IgE}

Total IgE was determined using a chemiluminiscent enzymoimmunoassay (Immulite-2000, Siemens Medical Solutions). Serum IgE levels $>170 \mathrm{IU} / \mathrm{mL}$ were deemed to be abnormally elevated [8].

\section{Serum-Specific IgE to Mixtures of Allergens (Multiallergen Screening Tests)}

Serum specific IgE to common aeroallergens was determined by means of a fluorometric immunoassay (UniCAP-Phadiatop-ImmunoCAP, Phadia [currently Thermo Fisher Scientific], hereafter, Phadiatop) [8]. The Phadiatop 
test is useful in mass-screening programmes because it is a commercially available variant of serum specific IgE assays based on the simultaneous testing for specific IgE to a mixture of relevant allergens causing common inhalant allergies. The test is qualitative, that is, either positive or negative when the fluorescence response is, respectively, higher or lower than that of the reference serum. A positive result indicates the presence of specific serum IgE against common inhalant allergens.

\section{Serum Specific IgE to Hymenoptera Venom Components}

Serum sIgE to whole Apis mellifera (honeybee) venom and Vespula species (wasp) venom was measured using the Immuno-CAP-250 system (Thermo Fisher Scientific) and expressed in $\mathrm{kU}_{\mathrm{A}} / \mathrm{L}$ [13]. Determination of $\operatorname{sIgE}$ to hymenoptera venom components was performed in a subsample of 26 alcoholic patients with positive sIgE to CCDs. The molecular components of hymenoptera venoms included phospholipases from honeybee and wasp (Api m 1 and Ves $\mathrm{v} 1$, respectively), hyaluronidases from honeybee and wasp (Api $\mathrm{m} 2$ and Ves $v 2$, respectively), and antigen 5 from wasp (Ves v 5). Natural honeybee phospholipase A2 (Api m 1) was obtained from Sigma-Aldrich. Recombinant honeybee venom hyaluronidase (Api m 2) was expressed in baculovirusinfected insect cells, purified and characterized as previously reported $[22,23]$, and kindly provided by the authors of the studies using the ADVIA-Centaur. Wasp venom allergens were purified from lyophilized venom (ALK-Abelló Source Materials), as indicated [24,25]. Natural venom components are glycosylated proteins, with the exception of wasp antigen 5 (Ves v 5) and wasp phospholipase (Ves v 1) [26]. Recombinant proteins obtained in the baculovirus-infected cell model are also glycosylated [27]. Purified venom components were labelled with biotin, and the levels of specific IgE to these allergens were tested using the ADVIA-Centaur platform (Siemens Medical Solutions Diagnostics) and expressed in kU/L [25].

\section{Serum-Specific IgE to Cross-reactive Carbohydrate Determinants}

Serum sIgE to the glycan MUXF (o214) in the 138 alcoholic patients was determined by ImmunoCAP (Thermo Fisher Scientific). The results were reported elsewhere [13]. The MUXF notation refers to the substitutions (mannose, unsubstituted, xylose, fucose) to the backbone of $2 \mathrm{~N}$-acetyl-glucosamines and a mannose that is common to all $\mathrm{N}$-glycans $[17,18]$. The MUXF glycan is widespread in nature and is the only glycan in the pineapple protein bromelain $[17,18]$. Natural bromelain is included in the ISAC assay (Thermo Fisher Scientific). Since sensitization to bromelain is very rare, the presence of bromelain-sIgE is considered indicative of sensitization to $\mathrm{CCD}[17,18]$. We also determined $\operatorname{sIgE}$ to horseradish peroxidase (HRP) in cases studied on the ADVIA platform. Horseradish peroxidase mainly contains MMXF-type (mannose, mannose, xylose, fucose) N-glycans. Sensitization to the HRP protein is also very rare; therefore, the presence of HRP-sIgE is considered indicative of sensitization to CCD $[17,18]$. Natural hymenoptera venom components commonly bear MMF3F6 (mannose, mannose, not xylosylated, and doubly fucosylated) N-glycans $[17,18]$.

\section{Serum Specific IgE to an Array of Allergen Components}

Determination of $\mathrm{sIgE}$ in the ISAC microarray (Thermo Fisher Scientific) was available in a subsample of 18 alcoholic patients with positive sIgE to CCDs by ImmunoCAP. In order to further define the profile of multiple positive sIgE results in CCD-positive alcoholic patients, their results were compared with those of 36 patients (12 males; median age, 34 years; range, 20-79 years) with respiratory allergy, polysensitization to aeroallergens, and no history of alcohol abuse who were attended at an allergy clinic in the same area during 2007-2009. The allergen microarray chip immunoassay was the same in all individuals and contained 103 allergen components from 43 allergen sources, including a marker of sensitization to CCD (natural bromelain, nAna c 2). The commercial array of allergens in the ISAC is constantly changing, and the composition of the version used was only available up to 2011 . Following the manufacturer's instructions, $20 \mu \mathrm{L}$ of patient serum was pipetted onto the chip, and specific antibodies for the allergens attached to the chip surface were left to bind for a 2-hour incubation period. Following a buffer wash, bound IgE antibodies were detected with a fluorescence-labelled anti-IgE antibody. The chip was read in a fluorometer, and fluorescent signal units were interpolated into ISAC standardized units (ISU), which correspond to IgE antibody levels in the $\mathrm{ng} / \mathrm{mL}$ range. This technique is a semi-quantitative test. Values of 0.3 ISU or higher were regarded as positive.

\section{Statistical Analysis}

The Mann-Whitney test was used to compare numerical variables between groups, the $\chi^{2}$ test and Fisher exact test were used to compare proportions, and the Spearman rank test was used to assess correlations. The incidence rate was based on person-years calculated from the date of hospital admission until death or until the last reliable contact with the health system, to account for potential misclassification owing to change of residence. Two-tailed $P$ values lower than .05 were considered statistically significant.

\section{Results}

\section{Total Serum IgE}

High serum total $\mathrm{IgE}$ concentrations $(>170 \mathrm{IU} / \mathrm{mL})$ were observed in 78/138 (57\%) alcoholic patients, with concentrations $>1000 \mathrm{IU} / \mathrm{mL}$ in 21 (15\%). Among the 110 SPT-negative patients, $59(54 \%)$ displayed IgE concentrations $>170 \mathrm{IU} / \mathrm{mL}$ and $14(13 \%)$ displayed IgE concentrations $>1000 \mathrm{IU} / \mathrm{mL}$; among the $28 \mathrm{SPT}$ positive patients, $19(68 \%)$ displayed $\operatorname{IgE}$ concentrations $>170 \mathrm{IU} / \mathrm{mL}$ and $7(25 \%)$ displayed IgE concentrations $>1000 \mathrm{IU} / \mathrm{mL}$. These differences between SPT-positive and SPT-negative patients in the proportions of increased IgE were not statistically significant $(P>.05)$.

\section{Multiallergen IgE Screening Tests}

A total of 70 of 138 patients $(51 \%)$ had a positive multiallergen screening test result (Phadiatop). While most of the SPT-positive patients (24/28 individuals, $86 \%)$ were 


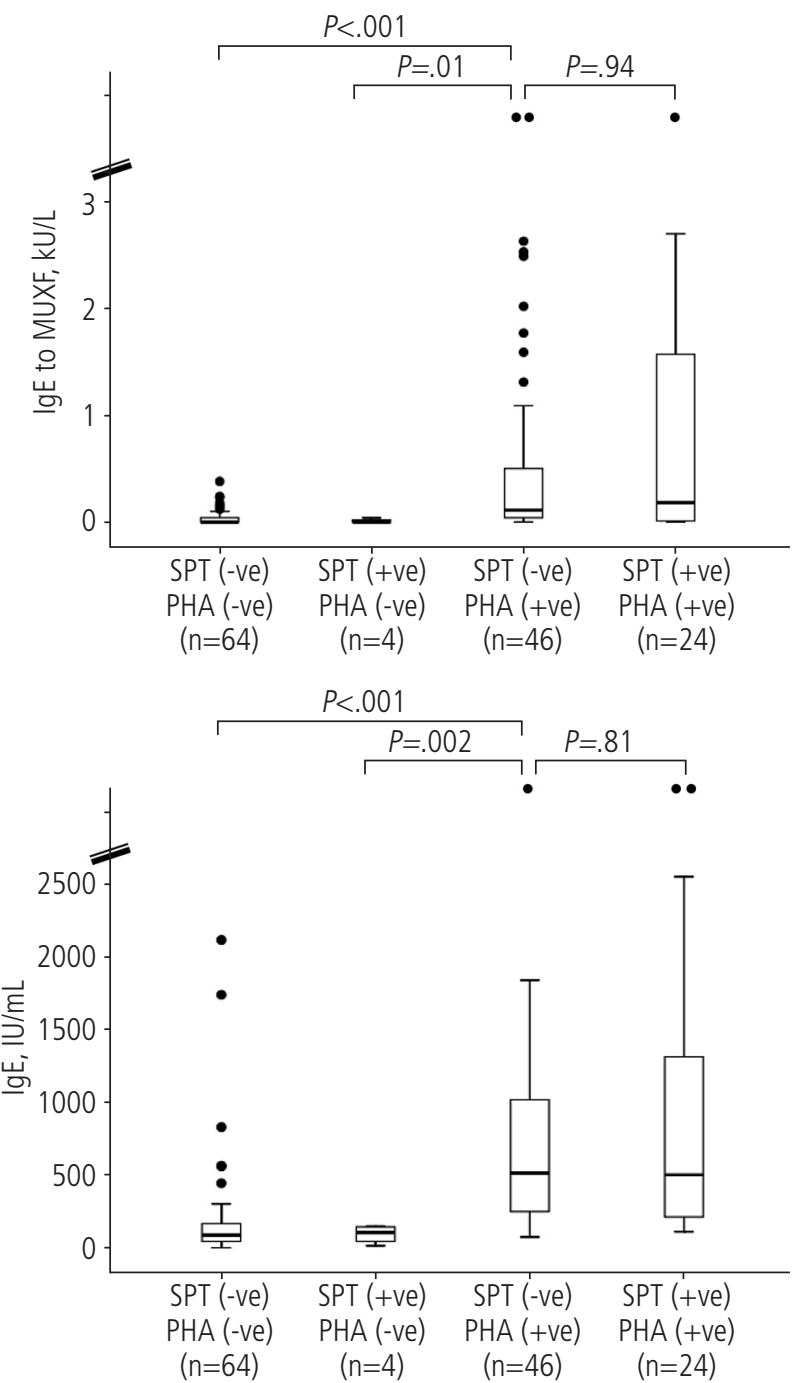

Figure 1. Serum concentrations of IgE specific to cross-reactive carbohydrate determinants (MUXF, top) and total IgE (bottom) in a sample of 138 alcoholics, stratified according to the results of skin prick tests (SPTs) and multiallergen IgE (Phadiatop [PHA]) results. (+ve) indicates positive; (-ve), negative.
Phadiatop-positive, a sizeable proportion of SPT-negative patients (46/110 individuals, 42\%) were also Phadiatoppositive. These apparently false-positive Phadiatop results were closely linked to higher serum concentrations of total IgE and sIgE to CCDs (Figure 1). There was also a significant correlation between total IgE and SIgE to MUXF (coefficient, $0.639 ; P<.001)$. A total of 47 out of 138 patients $(34 \%)$ showed sIgE to MUXF $\geq 0.1 \mathrm{kU}_{\mathrm{A}} / \mathrm{L}$, and $26(19 \%)$ showed $\operatorname{sIgE}$ to MUXF $\geq 0.35 \mathrm{kU}_{\mathrm{A}} / \mathrm{L}$.

\section{Serum Specific IgE to Allergen Components in CCD-Positive Patients}

The results of sIgE to whole hymenoptera venom and hymenoptera venom components in the $26 \mathrm{CCD}$-positive patients are shown in Table 1. Nearly all CCD-positive patients displayed dual ImmunoCAP-IgE positivity to honeybee and wasp whole venom extracts. None of these patients reported a history of hymenoptera venom allergy at baseline. After a median of 166 months of follow-up (range, 5-193 months), only 1 patient (a 50-year-old man with baseline honeybee venom $\operatorname{SIgE}$ of $15.7 \mathrm{kU}_{\mathrm{A}} / \mathrm{L}$ and MUXF $\operatorname{sigE}$ of $2.0 \mathrm{kU}_{\mathrm{A}} / \mathrm{L}$ ) developed honeybee venom allergy and underwent specific immunotherapy (incidence rate, 0.35 cases per 100 personyears). As for venom components, a high proportion of patients had positive results to both recombinant (glycosylated) honeybee hyaluronidase and natural (also glycosylated) wasp hyaluronidase. Concentrations of sIgE to these glycoproteins were particularly high, namely, $>50 \mathrm{kU} / \mathrm{L}$ in $7 / 25$ individuals $(28 \%)$ and $3 / 26$ individuals (11\%) for honeybee and wasp hyaluronidase, respectively. Detectable concentrations of sIgE to nonglycosylated allergens such as wasp antigen 5 (Ves v 5) and wasp phospholipase (Ves v 1) were observed in nearly half of the patients (Table 1).

The results of sIgE to an array of 103 allergenic components in 18 CCD-positive patients are shown in Figure 2. Among the 12 individuals with negative SPT results to aeroallergens, the overall number of positive results on ISAC was 89/1236 (7\%). Most of these positive results corresponded to natural, glycosylated plant allergens, particularly from Phleum pratense (nPhl p 4 [berberine bridge enzyme]; 11/12 cases, 92\%), Cynodon dactylon (nCyn d 1 [grass group 1]; 11/12 cases,

Table 1. Serum Levels of Specific IgE to Hymenoptera Venoms and Their Components in 26 Heavy Drinkers Sensitized to Cross-Reactive Carbohydrates With No History of Systemic Reaction to Hymenoptera Stings

\begin{tabular}{lccccccc}
\hline & \multicolumn{2}{c}{ Whole Venom } & \multicolumn{2}{c}{ Phospholipases } & \multicolumn{2}{c}{ Hyaluronidases } & Antigen 5 \\
\hline & Honeybee & Wasp & $\begin{array}{c}\text { Honeybee } \\
\text { (Api m 1) }\end{array}$ & $\begin{array}{c}\text { Wasp } \\
\text { (Ves v 1) }\end{array}$ & $\begin{array}{c}\text { Honeybee } \\
\text { (Api m 2) }\end{array}$ & $\begin{array}{c}\text { Wasp } \\
\text { (Ves v 2) }\end{array}$ & $\begin{array}{c}\text { Wasp } \\
\text { (Ves v 5) }\end{array}$ \\
\hline Method & ImmunoCAP $^{\mathrm{a}}$ & ImmunoCAP & ADVIA $^{\mathrm{b}}$ & ADVIA & ADVIA & ADVIA & ADVIA \\
\hline $\begin{array}{l}\text { Median (and range) } \\
\text { of specific IgE, kU/L }\end{array}$ & 6.9 & 3.4 & 3.2 & 0.48 & 12.9 & 8.8 & 0.12 \\
Percentage with specific & $1.0-74.3)$ & $(0.21-56.9)$ & $(0-115)$ & $(0-119)$ & $(0.45-348)$ & $(0.12-112)$ & $(0-88.7)$ \\
IgE $\geq 0.35 \mathrm{kU} / \mathrm{L}, \mathrm{n} / \mathrm{N}$ & $(26 / 26)$ & $(25 / 26)$ & $(20 / 26)$ & $(13 / 26)$ & $(25 / 25)$ & $(24 / 26)$ & $(12 / 25)$ \\
\hline
\end{tabular}

almmunoCAP, UniCAP-250 system (Thermo Fisher Scientific) [13].

${ }^{b}$ ADVIA, ADVIA-Centaur system (ADVIA-Centaur (Siemens Medical Solutions Diagnostics). Allergens were natural (purified), with the exception of honeybee venom hyaluronidase (Api m 2), which was obtained by recombination in baculovirus-infected cells and was therefore also glycosylated. 


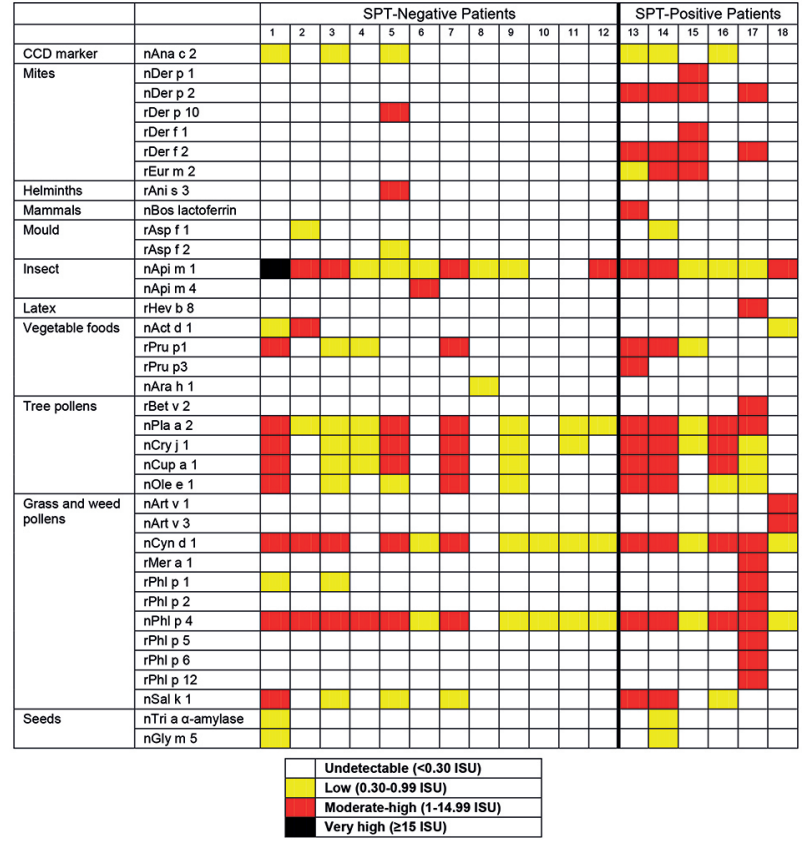

Abbreviation: SPT, skin prick test.

Figure 2. Representation of positive results of specific $\lg E$ (slgE) to 103 allergens in the ISAC microarray system in 18 alcoholic patients with positive slgE ( $\geq 0.35 \mathrm{kUA} / \mathrm{L})$ to cross-reactive carbohydrate determinants (CCDs) in ImmunoCAP. Serum slgE to the remaining allergen components proved to be negative in all patients, including components from crustaceans ( $r$ Pen a 1 , nPen i 1, nPen $\mathrm{m} 1$ ), helminths (rAni s 1), animal danders (rFel d 1, 2, and 4; rCan f 1, 2, and 3), mammals (nEqu c 3; nMus $\mathrm{m} \mathrm{1;}$;Bos d 4, 5, 6, and 8), fish (rCyp c 1, rGad c 1), avian (nGal d 1, 2 , 3, and 5), molds (rAlt a 1 and 6; rCla h 8; rAsp f 3, 4, and 6), arthropods (rBla g 1, 2, 4, 5, and 7), latex (rHev b 1, 3, 5, and 6), vegetable foods (nAct d 2, 5, and 8; rMal d 1; rApi g 1; rDau c 1; rAna o 2; rBer e 1; nAra h 2 and 3; rAra h 8; r Cor a 1.0101, 1.0401 and 8; nCor a 9), tree pollens (rAln g 1, rBet v 1, r Bet v 4, rPla a 1, nOle e 2), weed pollen (nAmb a 1, rPar j 2), grass pollens (rPhl p 7 and 11), and seeds (nSes i 1, nTri a 18, nTri a gliadin, rTri a 19.0101, rGly m 4 and 6). Recombinant components are denoted by ' $r$ ' and natural purified proteins by ' $n$ '. On SPT, the 6 positive patients were sensitised to mites; patients number 16 and 17 were also sensitised to Plantago lanceolata. ISU indicates ISAC standardized units; SPT, skin prick test.

92\%), Platanus acerifolia (nPla a 2 [polygalacturonase]; 9/12 cases, 75\%), Cryptomeria japonica (nCry j 1 [pectate lyase]; 7/12 cases, 58\%), Cupressus arizonica (nCup a 1 [pectate lyase]; 7/12 cases, 58\%), O europaea (nOle e 1 [common olive group 5]; 5/12 cases, 42\%), and Salsola kali (nSal k 1 [pectin methylesterase]; 4/12 cases, 33\%), frequently at lowto-moderate titers (Figure 2). Most SPT-negative patients were also positive to natural, glycosylated hymenoptera allergen from A mellifera (nApi m 1 [phospholipase A2]; 10/12 cases, $83 \%$ ). However, the same patients were negative to some natural plant allergen components from Actinidia deliciosa, Prunus persica, Arachis hypoagea, Olea europaea, Corylus avellana, Triticum aestivum, Sesamum indicum, Glycine max, Artemisia vulgaris, and Ambrosia artemiisifolia (Figure 2). Most SPT-negative patients had uniformly negative results to recombinant proteins related to plants, with the exception of rPru p1 (Prunus persica PR-10 protein), which was positive in $4 / 12$ cases $(33 \%)$. The same SPT-negative patients tended to be uniformly negative to proteins of mite, mold, helminth, crustacean, mammal, avian, fish, or arthropod (Blattella germanica), whether natural or recombinant. All of the 6 CCD-positive patients with positive SPT results to aeroallergens were sensitized to mites, and patients number 16 and 17 were also sensitized to $P$ lanceolata. The overall number of positive results on ISAC in SPT-positive patients was $75 / 618(12 \%)$. The pattern of positive results was similar to that in SPT-negative individuals, with the addition of specific sensitizations, particularly to mites, the most common aeroallergens in the area (Figure 2).

The profile of positive sIgE ISAC results in CCD-positive patients was different from that of nonalcoholic patients with respiratory allergy and multiple IgE sensitizations. A comparison of representative allergens is shown in Table 2. Thus, patients with respiratory allergy had the most common sensitization profile in our region, and whenever sIgE to profilin (represented by rBet v 2), nCyn d 1, and/or nPhl p 4 was positive, it was accompanied by positive results to other recombinant allergens from the same source (Table 2), suggesting genuine sensitization. However, the sensitization profile detected in alcoholic patients did not follow the same pattern, and only sIgE determinations with natural allergens were positive, with the exception of rPru $\mathrm{p} 1$. Moreover, alcoholic patients also showed uniform sIgE positivity to A mellifera (nApi m 1), which was absent in polysensitized allergic patients from the area (Table 2). These results suggest a role for CCD-bearing proteins in these false-positive results.

There was a significant correlation between SIgE to MUXF (o214) on ImmunoCAP and sIgE to MUXF-bearing natural bromelain (nAna c 2 [Ananas comosus]), the CCD marker on ISAC (Figure 3 ). However, only 6 out of 18 patients $(33 \%)$ with positive $\left(\geq 0.35 \mathrm{kU}_{\mathrm{A}} / \mathrm{L}\right)$ sIgE to CCDs (MUXF) on ImmunoCAP presented positive $\operatorname{sIgE}(\geq 0.3 \mathrm{ISU})$ to the $\mathrm{CCD}$ marker (bromelain) on ISAC. The correlation between $\operatorname{sigE}$ to the CCD marker (horseradish peroxidase) on the ADVIA platform and SIgE to bromelain on ISAC followed a similar pattern (Figure 3). The correlation between SIgE to horseradish peroxidase (ADVIA) and sIgE to MUXF (ImmunoCAP) was stronger and more consistent (Figure 3). The majority of patients $(19 / 26,73 \%)$ with positive $\left(\geq 0.35 \mathrm{kU}_{\mathrm{A}} / \mathrm{L}\right) \mathrm{sIgE}$ to CCDs (MUXF) on ImmunoCAP presented positive sIgE $\left(\geq 0.35 \mathrm{kU}_{\mathrm{A}} / \mathrm{L}\right)$ to the $\mathrm{CCD}$ marker (horseradish peroxidase) on ADVIA Centaur.

The concentrations of sIgE to MUXF on ImmunoCAP tended to correlate with serum total IgE concentrations (correlation coefficient, $0.411 ; P=.03$ ). The correlation between serum total IgE and sIgE to bromelain on ISAC (coefficient, $0.302 ; P=.23$ ) and sIgE to horseradish peroxidase on ADVIA (coefficient, $0.130 ; P=.23$ ) was weaker. There was a significant correlation between SIgE to CCD markers (as measured by any method) and sIgE to glycosylated allergen components, particularly from hymenoptera venoms (Api m 1, Api m 2, Ves v 2) and plants (nPhl p 4, nCyn d 1, nPla a 2, nCry j 1, nCup a 1 , nOle e 1 , and nSal k 1) (data not shown).

\section{Discussion}

We found increased total serum IgE, increased serum CCDsIgE, and subsequent positive sIgE results to glycosylated 
Table 2. Comparison of ISAC Results of IgE Specific to Representative Allergens in Alcoholic Patients With Sensitization to CCD on CAP and Polysensitized Patients With Respiratory Allergy From an Allergy Clinic

\begin{tabular}{|c|c|c|c|}
\hline $\begin{array}{l}\text { Allergen-sIgE Positivity } \\
(\geq 0.30 \text { ISU) }\end{array}$ & $\begin{array}{l}\text { Alcoholic Patients With } \\
\text { CCD-Specific IgE }(n=18)\end{array}$ & $\begin{array}{l}\text { Polysensitized Patients With Respiratory Allergy } \\
\text { From an Allergy Clinic }(\mathrm{n}=36)\end{array}$ & $P$ Value \\
\hline nAna c 2, No. (\%) & $6(33.3)$ & $0(0.0)$ & $<.001$ \\
\hline nApi m 1, No. (\%) & $16(88.8)$ & $0(0.0)$ & $<.001$ \\
\hline rPru p 1, No. (\%) & $7(38.8)$ & $1(2.7)$ & .001 \\
\hline nAct d 1, No. (\%) & $3(16.6)$ & $0(0.0)$ & .032 \\
\hline nPla a 2 , No. (\%) & $14(77.7)$ & $0(0.0)$ & $<.001$ \\
\hline nCry j 1, No. (\%) & $12(66.6)$ & $1(2.7)$ & $<.001$ \\
\hline rBet v 1, No. (\%) & $0(0.0)$ & $6(16.6)$ & .162 \\
\hline rBet v 2, No. (\%) & $1(5.5)$ & $9(25.0)$ & .137 \\
\hline nCup a 1, No. (\%) & $10(55.5)$ & $2(5.5)$ & $<.001$ \\
\hline nOle e 1 , No. (\%) & $9(50.0)$ & $1(2.7)$ & $<.001$ \\
\hline nArt v 1, No. (\%) & $1(5.5)$ & $1(2.7)$ & .999 \\
\hline nArt v 3, No. (\%) & $1(5.5)$ & $1(2.7)$ & .999 \\
\hline nCyn d 1, No. (\%) & $16(88.8)$ & $19(52.7)$ & .014 \\
\hline nSal k 1, No. (\%) & $7(38.8)$ & $0(0.0)$ & $<.001$ \\
\hline nPhl p 4, No. (\%) & $17(94.4)$ & $11(30.5)$ & $<.001$ \\
\hline Isolated $\mathrm{nPhl}$ p 4 positivity, No. $(\%)^{\mathrm{a}}$ & $14(77.7)$ & $0(0.0)$ & $<.001$ \\
\hline
\end{tabular}

aPositive specific IgE results to $\mathrm{nPhle} \mathrm{p} 4$ with negative results to rPhle p 1, rPhle p 2, rPhle p 5, rPhle p 6, and rPhle p 12.

plant and insect allergens in the alcoholic patients we studied. Similar findings have been reported elsewhere $[3,4,6-8,13,16]$. To our knowledge, this is the first study to show the prevalence of increased total serum $\operatorname{IgE}$ and positive multiallergen $\operatorname{sgE}$ test results after systematically categorizing alcoholic patients as atopic or nonatopic using a standard panel of SPTs. Among nonatopic (SPT-negative) alcoholic patients, $54 \%$ showed increased $(>170 \mathrm{IU} / \mathrm{mL})$ and $13 \%$ showed very high $(>1000 \mathrm{IU} / \mathrm{mL})$ serum total IgE concentrations. Furthermore, $42 \%$ of nonatopic alcoholic patients had a positive (ie, presumably false-positive) multiallergen IgE test in close relationship with the presence of CCD-sIgE. As expected, patients with positive CCD-sIgE on ImmunoCAP had positive results to multiple naturally glycosylated allergens on ISAC multiarray and to glycosylated hymenoptera venom components on ADVIA Centaur, although significant discrepancies in CCD-sIgE positivity were observed depending on the method used. Taken together, these results demonstrate that serological tests for allergy should be interpreted with caution in alcoholic patients.

Multiallergen sIgE tests are rarely used in allergy clinics but are intended for screening for allergic sensitization in primary care. In general populations, the test has significant specificity and the false-positive rate (ie, a positive multiallergen test in SPT-negative individuals) is lower than $10 \%$ [28]. In contrast, a third of all alcoholic patients admitted to hospital in the present series had false-positive results for the multiallergen sIgE. As in the general population [14,15,28], false-positive results in multiallergen tests in alcoholic patients are closely associated with the presence of CCD-sIgE. Indeed, tests that mix several allergens are particularly prone to interference from CCDs [18]. These findings indicate that multiallergen sIgE tests have lower specificity among alcoholic patients.

Alcoholics with CCD-sIgE had dual positivity of SIgE to honeybee and wasp venoms, as previously reported in this series [13]. Moreover, they displayed sIgE positivity to glycosylated phospholipases and, in particular, to hyaluronidases from both venoms. These findings may be of importance, since SPTs to hymenoptera venoms are frequently negative in cases of true allergy, and diagnosis of hymenoptera venom allergy often depends on intradermal tests, serum sIgE, and the clinical history, which may be less reliable in alcoholic patients [29]. The mechanisms for sensitization to CCDs in alcohol drinkers are not known. CCDs are probably the most common epitopes to which humans are exposed [17]. Exposure could derive from pollen inhalation, vegetable consumption, or hymenoptera stings. Circumstantial evidence supports the contention that the latter could be of particular importance. A lifetime history of hymenoptera stings is associated with sensitization to CCDs in patients without hymenoptera venom allergy [30]. CCD-sIgE concentrations increase after hymenoptera stings [31]. In the present series, a sizeable percentage (nearly 50\%) of alcoholic patients with CCD-sIgE showed positive sIgE to wasp antigen 5 (Ves v 5) and wasp phospholipase (Ves v 1), which are not glycosylated [26], suggesting that hymenoptera stings were probably common in this population. The fostering effect of alcohol consumption on IgE synthesis [3-11] could explain the high levels of sIgE to venom components in exposed persons. Unfortunately, the history of previous hymenoptera stings was not registered in the present cases. None of 138 
alcoholic patients reported hymenoptera venom allergy at baseline, and only 1 patient developed hymenoptera venom allergy during follow-up. Positive sIgE to hymenoptera venom components further exemplifies 2 aspects of the interference of CCDs in sIgE determinations. Firstly, sensitization to CCDs
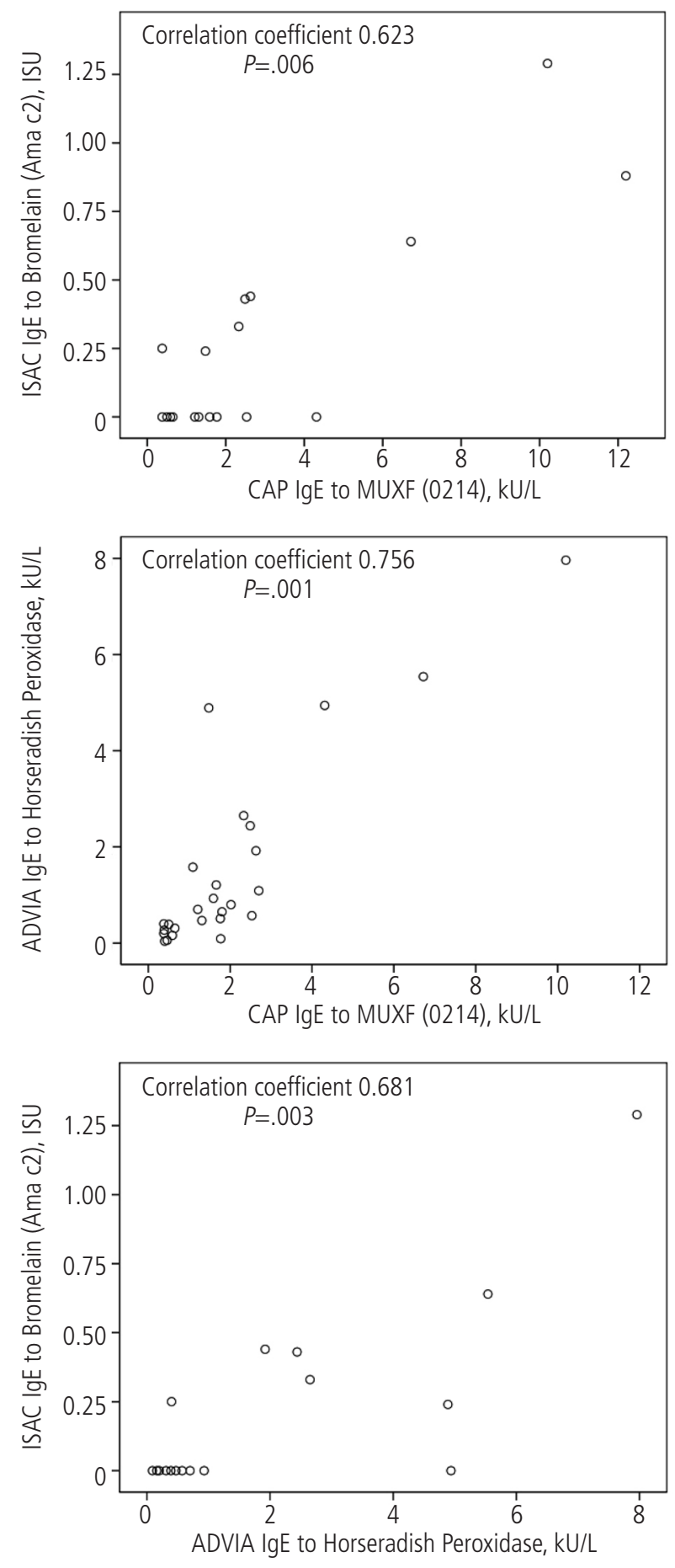

Figure 3. Correlation between markers of sensitization to cross-reactive carbohydrate determinants (CCDs) in alcoholic patients with positive slgE $(\geq 0.35 \mathrm{kUA} / \mathrm{L})$ to CCDs on ImmunoCAP. can interfere both with determination of sIgE to naturally glycosylated molecular components and with determination of sIgE to recombinant molecular components that are obtained in baculovirus-infected cells (such as honeybee venom hyaluronidase in the present study), which may be glycosylated [17]. In contrast, recombinant molecules that are obtained in prokaryotic organisms (bacteria) are not glycosylated [17]. Secondly, aside from ImmunoCAP, other devices supposedly less prone to interference from CCDs, eg, ADVIA Centaur [18], could also be affected.

Determination of sIgE to microarrays of allergen components is a promising tool for molecular diagnosis of allergy $[19,20]$. Our results confirm that the test instrument can also be affected by interference from CCDs [32-34]. In a subsample of alcoholic patients sensitized to CCDs, a uniform pattern of positive sIgE results was observed including - as expected-naturally glycosylated allergen components of plant and insect origin. Microarrays have a changing allergen composition; in fact, the device that was used for the present study changed its composition in recent versions. However, the composition of arrays commonly includes natural (n) plant and insect allergens that may be prone to interference from CCDs. Of note, nonatopic alcoholic patients sensitized to CCDs frequently showed IgE positivity to $\mathrm{nApi} \mathrm{m} 1$ from $A$ mellifera, nPhl p 4 from $P$ pratense, nCyn $\mathrm{d} 1$ from $C$ dactylon, nPla a 2 from $P$ acerifolia, nCry j 1 from $C$ japonica, nCup a 1 from $C$ arizonica, and nOle e 1 from $O$ europaea. A similar pattern was observed in atopic alcoholic patients, even in cases with negative results to the same allergens in SPT. However, the same patients more rarely had positive results to nAct $\mathrm{d} 1$ from kiwi and nSal k 1 from $S$ kali and had uniformly negative results to additional natural plant allergens, supporting the notion that the behaviour of these allergens as "CCD-bearing proteins" is not uniform. Of note, this pattern of apparent IgE polysensitization among alcoholic patients was entirely different from that of nonalcoholic polysensitized patients with respiratory allergy from the same area. Unexpected positivity to rPru p 1 (PR-10 from P persica) was observed in a sizeable number of alcoholic patients sensitized to CCDs. The same patients were negative to analogous PR-10 from Mal d 1 and Bet $\mathrm{v} 1$, suggesting that a positive result to $\mathrm{rPru} \mathrm{p} 1$ does not represent genuine sensitization in these cases. The exact method for obtaining rPru p 1 was not available from the manufacturer, and the reason for such marked sIgE positivity in alcoholics is unknown. Microarrays provide a large data load, which means that misinterpretation of data becomes a real risk when clinical information is unreliable. It should be noted that sIgE to the CCD marker used in the array (bromelain) proved negative in two-thirds of alcoholic patients with sIgE to MUXF on ImmunoCAP. Bromelain from pineapple (nAna c 2) is a well-recognized CCD marker that contains a single MUXF epitope $[17,18]$. For unknown reasons, which may include microarray methodology or allergen processing for the array, sIgE to the marker was not detected in most cases, thus further favoring misinterpretation of microarray results. More recent versions of the ISAC include the MUXF molecule instead of bromelain, and this could increase diagnostic accuracy. The peculiar profile of positive sIgE results to glycosylated natural allergens may be strongly indicative of sensitization to CCDs. Additionally, inhibition studies are a well-known strategy for 
confirming interference from CCDs [13,15,34]. Specifically, Holsweber et al [34] demonstrated the neutralizing effect of a CCD blocker against a group of well-known CCD-bearing proteins (nCyn d 1, nJug r 2, nCry j 1, nCup a 1, nOle e 1 , nPla a 1 , and $\mathrm{nPhl}$ p 4), most of which were involved in falsepositive results in the patients we report.

Our study is subject to a series of limitations. sIgE to molecular components was only determined in a small subset of patients with positive CCD-sIgE. As previously mentioned, the molecular components in the array are constantly changing, although interference from CCDs will remain problematic whenever natural plant or insect allergens are included. We did not perform inhibition experiments, which would have demonstrated that sIgE reactivity to glycosylated allergens was due to interference from CCDs $[13,15,34]$. This study included very heavy drinkers, with a median daily alcohol consumption of $120 \mathrm{~g}$ (12 standard drinking units). The results cannot be fully extrapolated to all alcohol drinkers, though previous studies have shown that less heavy and even moderate alcohol drinkers display higher IgE concentrations and higher rates of CCD-sIgE positivity than the nondrinking population [13-15].

Harmful alcohol use remains unrecognized by many clinicians, and specifically by allergologists for at least 2 reasons. Firstly, estimation of alcohol consumption is problematic and time-consuming. Clinical assessment of alcohol intake is often reduced to a simple question, such as "Do you drink?", and answers are often reduced to a simple statement such as "Average". Denial and minimization are hallmarks of alcohol abuse, with many individuals underreporting their use of alcohol [35]. A positive response including "in the last 24 hours" to additional questions such as "When was your last drink?" has a positive predictive value of $68 \%$ and negation has a negative predictive value of $98 \%$ for detection of alcohol abuse [36]. Although imperfect, effective strategies and short questionnaires can be used by clinicians [36]. A precise estimation of the average amount of alcohol consumption requires reviewing a standard day and summing up the number of units of alcohol (glasses of wine, beer, and spirits, each approximately equivalent to one standard unit or $10 \mathrm{~g}$ of pure alcohol). Secondly, the potential effect of alcohol consumption on immune responses is often underestimated. When investigating lifestyle factors while taking a history, clinicians tend to focus on smoking, particularly in patients with allergic respiratory disease. Yet, part of the effects on IgE responses which were previously attributed to smoking, could actually be due to the confounding effect of alcohol $[6,9,13]$. In summary, the prudent allergologist should include a questionnaire on alcohol consumption as a routine part of standard clinical practice. Results of serological tests for allergy should be interpreted carefully in alcoholic patients, who frequently display increased levels of total $\mathrm{IgE}$ and SIgE to CCDs, with subsequent widespread positivity of sIgE to glycosylated allergens and their components, irrespective of the method used.

\section{Acknowledgments}

The authors thank Dr. Zora Marković-Housley and Prof. Ulrich Muller for kindly providing the rApi $\mathrm{m} 2$ molecule used in these studies.

\section{Funding}

The study was supported by grant (PI16/01404) and by the Spanish Network for Addictive Disorders (Red de Trastornos Adictivos, RD16/0017/0018), both from the Carlos III Institute of Health (Instituto de Salud Carlos III, Spanish Ministry of Health) and FEDER funds.

\section{Conflicts of Interest}

The authors declare that they have no conflicts of interest.

\section{References}

1. Szabo G. Consequences of alcohol consumption on host defence. Alcohol Alcohol. 1999;34:830-41.

2. Szabo G, Bala S. Alcoholic liver disease and the gut-liver axis. World J Gastroenterol. 2010;16:1321-9.

3. Dominguez-Santalla MJ, Vidal C, Vinuela J, Perez LF, GonzalezQuintela A. Increased serum IgE in alcoholics: relationship with Th1/Th2 cytokine production by stimulated blood mononuclear cells. Alcohol Clin Exp Res. 2001;25:1198-205.

4. Gonzalez-Quintela A, Vidal C, Lojo S, Pérez LF, Otero-Antón E, Gude $F$, et al. Serum cytokines and increased total serum IgE in alcoholics. Ann Allergy Asthma Immunol. 1999;83:61-7.

5. Alonso M, Gomez-Rial J, Gude F, Vidal C, Gonzalez-Quintela A. Influence of experimental alcohol administration on serum immunoglobulin levels: contrasting effects on $\mathrm{IgE}$ and other immunoglobulin classes. Int J Immunopathol Pharmacol. 2012;25:645-55.

6. Gonzalez-Quintela A, Vidal C, Gude F. Alcohol, IgE and allergy. Addict Biol. 2004; 9:195-204.

7. González-Quintela A, Vidal C, Gude F, Tomé S, Lojo S, Lorenzo MJ, et al. Increased serum IgE in alcohol abusers. Clin Exp Allergy. 1995;25:756-64.

8. Campos J, Gude F, Quinteiro C, Vidal C, Gonzalez-Quintela A. Gene by environment interaction: the $-159 \mathrm{C} / \mathrm{T}$ polymorphism in the promoter region of the CD14 gene modifies the effect of alcohol consumption on serum IgE levels. Alcohol Clin Exp Res. 2006;30:7-14.

9. Linneberg A, Petersen J, Nielsen NH, Madsen F, Frølund L, Dirksen $A$, et al. The relationship of alcohol consumption to total immunoglobulin $E$ and the development of immunoglobulin $E$ sensitization: the Copenhagen Allergy Study. Clin Exp Allergy. 2003;33:192-8.

10. Gonzalez-Quintela A, Gude F, Boquete O, Rey J, Meijide LM, Suarez $\mathrm{F}$, et al. Association of alcohol consumption with total serum immunoglobulin $\mathrm{E}$ levels and allergic sensitization in an adult population-based survey. Clin Exp Allergy. 2003;33:199205.

11. Lomholt FK, Nielsen SF, Nordestgaard BG. High alcohol consumption causes high lgE levels but not high risk of allergic disease. J Allergy Clin Immunol. 2016;138:1404-13.

12. Bjerke T, Hedegaard M, Henriksen TB, Nielsen BW, Schiotz PO. Several genetic and environmental factors influence cord blood IgE concentration. Pediatr Allergy Immunol. 1994;5:88-94.

13. Gonzalez-Quintela A, Garrido M, Gude F, Campos J, Linneberg A, Lojo $S$, et al. Sensitization to cross-reactive carbohydrate determinants in relation to alcohol consumption. Clin Exp Allergy. 2008;38:152-60. 
14. Linneberg A, Fenger RV, Husemoen LL, Vidal C, Vizcaino L, Gonzalez-Quintela A. Immunoglobulin E sensitization to cross-reactive carbohydrate determinants: epidemiological study of clinical relevance and role of alcohol consumption. Int Arch Allergy Immunol. 2010;153:86-94.

15. Coutinho V, Vidal C, Garrido M, Gude F, Lojo S, Linneberg $A$, et al. Interference of cross-reactive carbohydrates in the determination of specific $\lg \mathrm{E}$ in alcohol drinkers and strategies to minimize it: the example of latex. Ann Allergy Asthma Immunol .2008;101:394-401.

16. Gonzalez-Quintela A, Gomez-Rial J, Valcarcel C, Campos J, Sanz $M L$, Linneberg $A$, et al. Immunoglobulin-E reactivity to wine glycoproteins in heavy drinkers. Alcohol. 2011;45:113-22.

17. Altmann F. The role of protein glycosylation in allergy. Int Arch Allergy Immunol. 2007;142:99-115.

18. Malandain H. IgE-reactive carbohydrate epitopes-classification, cross-reactivity, and clinical impact (2nd part). Eur Ann Allergy Clin Immunol. 2005;37:247-56.

19. Sastre J. Molecular diagnosis in allergy. Clin Exp Allergy. 2010;40:1442-60.

20. Jahn-Schmid B, Harwanegg C, Hiller R, Bohle B, Ebner C, Scheiner $\mathrm{O}$, et al. Allergen microarray: comparison of microarray using recombinant allergens with conventional diagnostic methods to detect allergen-specific serum immunoglobulin $\mathrm{E}$. Clin Exp Allergy. 2003;33:1443-9.

21. Campos J, Gonzalez-Quintela A, Quinteiro C, Gude F, Perez LF, Torre JA, et al. The $-159 \mathrm{C} / \mathrm{T}$ polymorphism in the promoter region of the CD14 gene is associated with advanced liver disease and higher serum levels of acute-phase proteins in heavy drinkers. Alcohol Clin Exp Res. 2005;29:1206-13.

22. Soldatova LN, Crameri R, Gmachl M, Kemeny DM, Schmidt M, Weber $M$, et al. Superior biologic activity of the recombinant bee venom allergen hyaluronidase expressed in baculovirusinfected insect cells as compared with Escherichia coli. J Allergy Clin Immunol. 1998;101:691-8.

23. Soldatova LN, Tsai C, Dobrovolskaia E, Marković-Housley Z, Slater JE. Characterization of the N-glycans of recombinant bee venom hyaluronidase (Api $\mathrm{m} 2$ ) expressed in insect cells. Allergy Asthma Proc. 2007;28:210-5.

24. King TP, Kochoumian L, Joslyn A. Wasp venom proteins: phospholipase A1 and B. Arch Biochem Biophys. 1984;230:1-12

25. Monsalve RI, Vega A, Marqués L, Miranda A, Fernández J, Soriano $V$, et al. Component-resolved diagnosis of vespid venom-allergic individuals: phospholipases and antigen 5 are necessary to identify Vespula or Polistes sensitization. Allergy. 2012;67:528-36.

26. Henriksen A, King TP, Mirza O, Monsalve RI, Meno K, Ipsen $\mathrm{H}$, et al. Major venom allergen of yellow jackets, Ves $\vee 5$ : structural characterization of a pathogenesis-related protein superfamily. Proteins. 2001;45:438-48.

27. Harrison RL, Jarvis $\mathrm{DL}$. Protein $\mathrm{N}$-glycosylation in the baculovirus-insect cell expression system and engineering of insect cells to produce "mammalianized" recombinant glycoproteins. Adv Virus Res. 2006;68:159-91.
28. Gonzalez-Quintela A, Garrido M, Gude F, Campos J, Lojo S, Linneberg $A$, et al. Discordant positive results of multiallergen immunoglobulin $E$ tests in relation to crossreactive carbohydrate determinants and alcohol consumption. J Investig Allergol Clin Immunol. 2009;19:70-1.

29. Carballada FJ, González-Quintela A, Núñez-Orjales R, Vizcaino $L$, Boquete M. Double (honeybee and wasp) immunoglobulin E reactivity in patients allergic to Hymenoptera venom: the role of cross-reactive carbohydrates and alcohol consumption. J Investig Allergol Clin Immunol. 2010;20:484-9.

30. Vidal C, Sanmartín C, Armisén M, Rodríguez V, Linneberg A Gonzalez-Quintela A. Minor interference of cross-reactive carbohydrates with the diagnosis of respiratory allergy in standard clinical conditions. Int Arch Allergy Immunol. 2012;157:176-85.

31. Kochuyt AM, Van Hoeyveld EM, Stevens EA. Prevalence and clinical relevance of specific immunoglobulin $E$ to pollen caused by sting-induced specific immunoglobulin $E$ to crossreacting carbohydrate determinants in Hymenoptera venoms. Clin Exp Allergy. 2005;35:441-7.

32. Cabauatan CR, Lupinek C, Scheiblhofer S, Weiss R, Focke-Tejkl $\mathrm{M}$, Bhalla $\mathrm{PL}$, et al. Allergen microarray detects high prevalence of asymptomatic lgE sensitizations to tropical pollen-derived carbohydrates. J Allergy Clin Immunol. 2014;133:910-4.

33. Villalta D, Conte M, Asero R, Da Re M, Stella S, Martelli P. Isolated IgE reactivity to native walnut vicilin-like protein (nJug $r$ 2) on ISACTM microarray is due to cross-reactive carbohydrate epitopes. Clin Chem Lab Med. 2013;51:1991-5.

34. Holzweber F, Svehla E, Fellner W, Dalik T, Stubler S, Hemmer W, et al. Inhibition of IgE binding to cross-reactive carbohydrate determinants enhances diagnostic selectivity. Allergy. 2013;68:1269-77

35. Skotzko CE, Vrinceanu A, Krueger L, Freudenberger R. Alcohol use and congestive heart failure: incidence, importance, and approaches to improved history taking. Heart Fail Rev. 2009;14:51-5

36. Fiellin DA, Reid MC, O'Connor PG. Screening for alcohol problems in primary care: a systematic review. Arch Intern Med. 2000;160:1977-89.

\section{Manuscript received November 27, 2017; accepted for publication August 23, 2018.}

\section{- Arturo Gonzalez-Quintela}

Departamento de Medicina Interna

Hospital Clínico Universitario

15706 Santiago de Compostela, Spain

E-mail: arturo.gonzalez.quintela@sergas.es 